\title{
Effects of Multiple Risks on Farm Income and Willingness to Pay for Agricultural Insurance: A Case Study of the Greater Accra Region in Ghana
}

\author{
Frederick Murdoch Quaye ${ }^{1}$ \\ ${ }^{1}$ College of Business, Albany State University, Albany, Georgia, USA \\ Correspondence: Frederick Murdoch Quaye, College of Business, Albany State University, Albany, Georgia, \\ USA. E-mail: frederick.quaye@asurams.edu
}

Received: February 25, 2016

Accepted: March 12, 2016

Online Published: May 25, 2016

doi:10.5539/ijef.v8n6p1

URL: http://dx.doi.org/10.5539/ijef.v8n6p1

\begin{abstract}
This paper analyzes the determinants of farm income among farmers producing crops and animals in the Greater Accra Region of Ghana. It further estimates the willingness to pay for agricultural insurance by farmers. The farm income function was evaluated using a logarithmic function in which farm income is regressed as a function of determinants affecting it. The econometric results suggest that gender, education, farm size, farming experience, fertilizer usage and input cost all have a positive and statistically significant association with farm income. The results indicate that when investing in agriculture in the study region, weather hazards and pest and disease attacks are two important risk factors that need to be considered in the implementation of insurance policies since they have and statistically significant negative associations with farm income. The paper further observes that weather and pest/disease attacks are two significant risk factors that tend to influence farmers' willingness to adopt and pay for agricultural insurance.
\end{abstract}

Keywords: farm income, revenue function, insurable agricultural risks, determinants of farm income, agricultural insurance

\section{Introduction}

Agriculture is the mainstay of Ghana's economy and accounts for more than 20 percent of the nation's GDP (ISSER, 2014). Even though its share has been reducing over the past couple of years, the sector still remains a relevant one towards development. More than half the population of the country is formally or informally involved in agricultural production. About 3.4 million households in Ghana own or operate a farm or keep livestock (GLSS, 2008). Agriculture predominantly occurs in the rural areas, involving about 85 percent of rural households and only 15 percent of urban households. Most of these farmers are subsistence farmers and about 80 percent of the operated farms are smallholder farms (GLSS, 2008). Most part of the farming population relies mainly on only their farm income, especially those living in the rural areas. One windfall is that, because farming is not very mechanized across the country, farm incomes generated are very low and thus poverty is very prevalent in farming communities. According to MoFA (Ministry of Food and Agriculture) 2010, small-scale farmers experience the highest incidence of poverty with 60 percent of food-crop farmers falling below the poverty line.

The Greater Accra Region is located in the southern part of Ghana and it is the capital city of the country. It has a population of almost 4.5 million representing about 18 percent of the total population of the entire ten regions (Population Census, 2010). It has a farming population of about 10 percent of the total population of the region. This shows that, even though the predominant sectors in this capital city are the manufacturing and services sectors, farming activities are also of significant importance. Farming activities in the region include crop cultivation (mainly maize, rice, cassava, and water melon and vegetables such as tomato, garden eggs, pepper, okra, lettuce, onion, cucumber and cabbage) and animal husbandry, mainly sheep and goats, fowls and pigs (MoFA, 2010).

Farm income refers to the amount an individual makes working on a farm either as a farmer or a hired laborer. As defined by Anriquez et al. farm income is defined as farm related income excluding labor income from off-farm employment as well as pensions and transfers. The farm work might include cultivating, operating, and 
managing the farm and the farm could either have crops, dairy, poultry, fish or the combination of any of these. In this context, farm income is defined as the entire average amount made from farming activities on individual farms for the period of five years. Farm income has been an uncertain variable in the Greater Accra Region due to several factors. Studies done by Biggs et al. (2011), El-Osta (2011) and Mabe et al. (2010) suggest that factors which affect farm income include age, education, gender, government policy, marital status, farming practices, access to extension services, credit availability and the marketing system. A study done by Bravo-Ureta et al (2005) suggest that farm income is a function of diversification, practices, structures, forestry, family labor, hired labor, cost, distance, credit, education and age. These studies and most others do not focus on the shock and risk aspects of the factors affecting farm income. Studies done in agricultural insurance show that shocks are very important determinants of farm income since they could reduce the income very drastically at any point in time. This study seeks to find the impact of some of these generally known physical factors in addition to certain agricultural shocks on annual farm income in the Greater Accra Region of Ghana.

Insurance in the agricultural sector is a very important issue but just recently received attention in Ghana. Until recently, governments since independence have attempted to modernize and increase the productivity of Ghana's agriculture through mechanization. This policy has often involved the subsidization of machinery and equipment as well as encouraging farmers to acquire them through hire purchase schemes. However, it is equally very important to provide some amount of security to farmers who take up the risks of using more and improved inputs. This would eliminate the fear of incurring high losses in the event of low yields due to certain various circumstances.

According to an analysis by Stutley (2010), Ghana loses an average of 5.5\% of the national production of the principle food crops due to climatic, biological and natural perils. The analysis was conducted for the eight main food crops grown in Ghana including maize, rice, cassava, yams, millet, sorghum, groundnuts and plantain. This thus presents good evidence why agriculture should be encouraged more in the country. The Ghana Agricultural Insurance Program (GAIP) started to provide agricultural insurance for Ghana in 2011. It provides agricultural insurance products (Note 1) for the country and currently also provides a risk management tool for the adverse effects of climate change and other risks to agricultural production.

The paper adds to the literature by providing an empirical analysis of farm income determination using both non-shock and shock factors specifically in the Greater Accra Region. It also shows factors that significantly affects farmers' willingness to enroll for agricultural insurance, and this information could be utilized by government as well as the 19 insurance companies (under the GAIP) that currently sell agricultural insurance products.

The rest of this article is organized as follows. The next section gives an overview of the relevant related literature, followed by a discussion of the conceptual framework and empirical model. The following section gives a description of the data used. The empirical results are then presented and discussed in the subsequent section. The paper then ends with some concluding remarks and policy recommendations.

\section{Literature Review}

Some studies have tried to develop models that would determine the best possible incomes that farmers could generate from their farming activities in specific geographical areas. Hattink et al. (1998) developed a cross-sectional profit function different from the usual time series analysis in order to determine the supply response of cocoa in Ghana. They argued that, the cross section model is stronger in conceptual sense since it is more firmly rooted in the neoclassical theory than the time series models. They found out that, cocoa producer price has only limited short-run effects on cocoa production and that cocoa pricing policies should be focused on short term plans. Henning et al. (2007) also developed a farm household revenue model to analyze price responses of farm households in the Mid-Western part of Poland. The model incorporated various types of transaction costs and labor heterogeneity and the results showed that the transactions and labor significantly affect the household income and consequently the household behavior.

Some other studies like this study have also focused on analyzing the effects of the determinants which affect farm revenue or income using different approaches and analytical procedures. Lopez et al. (2003) used a flexible farm revenue functional form and regressed the determinants on farm revenue per capita in Brazil. The determinants they analyzed were, inputs used per capita, land per capita, education of the household head, labor per capita, a dummy representing mechanized farming or not, family size, age of head of household and location of farm. They found out that, there is a very high degree of correspondence between the size of the farm operated by the farmer and his/ her level of income. Certain characteristics such as age and education also affect the farm income of the farmers significantly. They also realized that, the level of technology used significantly affected 
farm income to a very great extent. A much similar study was done by Anriquez et al. (2006) in Pakistan where they also tried to find the important determinants affecting the amount of revenues received by farmers. They emphasized more on the farm size by trying to analyze the effect a small reduction in farm size would have on the viability of the farm and eventually, on the farm income generated by the farmer. They regressed farm revenue as a function of age of household head, household size, education of the head, input cost, capital, informal credit, land owned, land operated and access to water. They estimated four different regressions and in each case regressed using four categories of land size which were landless, small farm size ( $<4$ acres), medium farm size (4-20 acres) and large farm size ( $>20$ acres). They found out that, medium and large farms had more revenue returns than the smaller and landless ones. They also observed that small and medium farms show a higher productivity than the larger farms. Of importance to their study, the results showed that the land markets in Pakistan were not efficiently working and hence made losses even when farm revenues were high. A recent study was done by Mishra et al. (2011) to estimate the income of U.S. farm households. Their results confirmed the findings of previous studies that, farm income is closely related to age of the operator, education, occupation, farm size, location and number of earners in the household. They observed that income is a significant determinant of household wealth. They also observed that, the wealth-income curve is nonlinear, upward sloping, and convex and using the Hausman's specification test, they indicated that variations in farm household wealth is better explained by estimated permanent income than observed total household income.

\subsection{Sources of Income of Rural Farm Households in Ghana}

Mostly, farmers and their households generate income from other sources apart from their farming activities. Because of this reason, some studies have estimated the total income (both farm and non-farm income) generated by farmers as a function of their determinants. For this study, such an idea was not considered because in the Greater Accra Region, farming is mainly done by rural farmers who acquire most of their income from their farming activities and as such makes the non-farm income somehow insignificant as a value. Table 1 shows the acquisition of average income by rural farmers in Ghana and thus, a generalization could be made for all the rural settlers who indulge in farming.

Table 1. Source of income for rural farmers

\begin{tabular}{lcccc}
\hline Rural Area & $\begin{array}{c}\text { Average Annual Farm } \\
\text { Income (\$) }\end{array}$ & $\begin{array}{c}\text { Average Annual Non-Farm } \\
\text { Income (\$) }\end{array}$ & $\begin{array}{c}\text { Total Average Annual } \\
\text { Income (\$) }\end{array}$ & $\begin{array}{c}\text { \% Farm Income of } \\
\text { Total Income }\end{array}$ \\
\hline Rural Coastal & 875 & 368 & 1,243 & $70.39 \%$ \\
Rural Forest & 724 & 323 & 1,047 & $69.16 \%$ \\
Rural Savanna & 1466 & 232 & 1,698 & $86.34 \%$ \\
\hline
\end{tabular}

Source: Author's Computation based on GLSS data.

The above computation shows that, farmers make a very significant proportion of their income from farming activities (in this case the Greater Accra Region), and thus a study to identify the significant determinants is a very justifiable cause.

Since the inception of the agricultural insurance program in the country, there have been a few number of studies conducted with regards to the topic. Going forward in the paper, some of the relevant ones are reviewed. Very much related to this paper are two 'willingness-to-pay for agricultural insurance' studies. Kwadzo et al. (2013) examined food crop farmers' willingness to participate in market-based crop insurance scheme in the Kintampo North Municipal of Ghana, using primary data solicited from 120 farmers in April 2010. They estimated the farmers' willingness to participate in a hypothetical market-based insurance scheme using the contingent valuation method. Their results reveal that the mean willingness to pay premium for a hypothetical loss of GH $\phi$ 1,000 of farm income is $\mathrm{GH} \notin 24.43$. The minimum and maximum willingness to pay premium, in the insurance scheme are $\mathrm{GH} \phi 5.00$ and $\mathrm{GH} \phi 80.00$ respectively. Their results also show that farm size, family size and diversification via livestock are factors that influence farmers' willingness to participate in crop insurance. Danso-Abbeam et al. (2014) also studied the willingness of cocoa farmers to pay for cocoa price insurance in the Ghana. They employed an independent double-hurdle model to determine factors influencing farmer's adoption of cocoa price insurance and the premium farmers are willing to pay. Their empirical results revealed that farmers' interest in cocoa price insurance was affected by range of explanatory variables such as marital status, number of years in cocoa farming, educational attainment, household size, farm size, ownership of farm land for farming, age of cocoa farm, age squared of cocoa farm, farmers being aware of the insurance scheme and income 
from cocoa farm. In addition, the premium farmers were willing to pay was significantly influenced by marital status, educational attainment, ownership of farm land for farming, farmer's awareness of insurance scheme and income from cocoa farm.

In a different dimension, Karlan et al. (2014) sought to test the importance of capital constraints and uninsured risk, separately and together, as financial market imperfections hindering optimal investment by smallholder farmers. They employ multi-year, multi-arm randomized trial with cash grants, rainfall insurance grants and rainfall insurance sales in the northern part of Ghana. They observe that uninsured risk is a binding constraint on farmer investment, meaning when farmers are provided with insurance against the primary catastrophic risk they face, they are able to find resources to increase expenditure on their farms. They also show that there is sufficient demand to support a market for rainfall insurance. They further observe that, at an actuarially fair price, 40 to 50 percent of farmers demand index insurance, and they purchase coverage for more than 60 percent of their cultivated acreage. From their data, they observe as well that demand for insurance in subsequent years strongly increased with farmers' own receipt of insurance payouts, receipt of payouts by others in the farmer's social network and with recent poor rain in the village. Another paper that is noteworthy is Nunoo et al.'s (2014) study which provides the literature with information on the state of provision of agricultural insurance as a means of protecting financial investment in agricultural productivity in Ghana, since its implementation. They also look at issues arising from empirical evidence on agricultural insurance provision and link them to scholarly articles on these issues. They observe that there has been considerable effort from the German Development Cooperation, the Ghana National Insurance Commission and government ministries and agencies, the Insurance sector in Ghana and stakeholder institutions leading to the creation of an agricultural insurance provider in Ghana. They however note that the system is facing major challenges resulting primarily from the inability of the state to provide the needed policy and regulatory support that will assist the insurance sector in the development and delivery of the agricultural insurance products.

\section{Conceptual Framework and Empirical Models}

The emphasis of this study is to analyze the effects that some agricultural shocks or insurable agricultural risks have on the amount of farm income generated by farmers. Farm Income is defined in this study as the average income farmers make from their farming activities on individual farms for the period of five years. Consistent with the studies done by Bravo-Uretaa et al. (2006), Anriquez et al. (2006) and Lopez et al. (2003), the relationships normally constructed for farm revenue functions are those between farm revenue as the dependent variable, and natural capital (land, livestock, crops etc.) and human capital (education, experience, age, other demographic attributes etc.). The study thus follows this theoretical framework in addition to some agricultural shocks that affect the productivity of farmers.

The theoretical farm revenue function is thus given as:

$$
\text { FaInco }=f(\text { Age, Sex, Educ, FaSi, FaEx, PdnTyp, Fert, InpCo, Wthr, Fire, Thef, Pada) }
$$

Where;

Age $=$ Age of Farmer, Sex $=$ Gender of farmer, Educ $=$ Formal Educational level of farmer, FaSi $=$ Farm Size FaEx $=$ Farming Experience, PdnTyp $=$ Production Type, Fert $=$ Fertilizer Usage, InpCo $=$ Input Cost of Production, $\mathrm{Wthr}=$ Unfavorable/ bad weather, Fire $=$ Fire Outbreak, Thef $=$ Theft of Agricultural produce or implement and Pada $=$ Pest and Disease attacks.

Following the logarithmic farm revenue function used by Bravo-Uretaa et al. (2006), this study also analyzes farm income as a logarithm function of the independent variables. Age squared and Education squared are also estimated to find whether the estimates of very old farmers and highly educated farmers had consistent results as that of Age and Education respectively. Production type is estimated as a dummy with three categories, and therefore has two dummies. The first category which is the base or reference point refers to farmers who cultivate only crops, the second category is farmers who cultivate only livestock and the third category is farmers who cultivate both crops and animals.

As estimated by Anriquez et al. (2006), this paper also estimates an interaction between farm size and farming experience and an interaction between gender and education.

The empirical model is thus given as;

$$
\begin{gathered}
\operatorname{In}(\text { FaInco })=\beta_{0}+\beta_{1} \text { Age }+\beta_{2} \text { Age } 2+\beta_{3} \text { Sex }+\beta_{4} E d u c+\beta_{5} E d u c^{2}+\beta_{6} \text { MaleEdu }+\beta_{7} F a S i \\
+\beta_{8} F a E x+\beta_{9} F a S i * F a E x+\beta_{10} \text { PdnTyp }+\beta_{11} \text { Fert }+\beta_{12} \operatorname{In}(\operatorname{InpCo})+\beta_{13} \text { Wthr }+\beta_{14} \text { Fire }+\beta_{15} \text { Thef }+\beta_{16} \text { Pada }+e_{i}
\end{gathered}
$$


Where $\ln =$ natural logarithm

MaleEdu $=$ Interaction between gender and education

$\mathrm{FaSi} \mathrm{FaEx}=$ Interaction between Farming Size and Farming Experience

ei $=$ error term

Hypothesis; $\mathrm{H}_{0}: \beta_{\mathrm{i}}=0 ; \mathrm{H}_{\mathrm{A}}: \beta_{\mathrm{i}} \neq 0$

The Ordinary Least Squares (OLS) method is used in this study to estimate the various parameters of the empirical model. This is because the OLS method is best, linear and unbiased (BLU). Thus, among all linear unbiased estimators, it exhibits the lowest variance (Wooldridge, 2008). Also, the OLS method is simple to use. It is therefore assumed in this study that, the expectation of the error term is supposed to be zero.

The supply of agricultural insurance in general is affected by the occurrence of risks or otherwise known as farm perils such as thefts, floods, hailstorms, droughts, fire outbreaks etc. and some of these risks are likely to affect the demand of agricultural insurance by insurance companies. According to Olubiyo (2009), perils which could affect the demand of agricultural insurance by farmers in the sub-region include bad weather (floods and droughts), fire outbreaks, thefts and pest and disease attacks on farm produce. Practically, factors such as age, level of education, farm size and income levels of farmers may also influence the demand and supply of agricultural insurance by farmers and insurance companies respectively.

\subsection{Detailed Variable Description}

Age: refers to the age of the individual farmers enumerated. It is expected that, as the farmers get older, they would be more willing to insure their agricultural assets due to experiences they encounter from risks.

Education: defined as the level of education attained by the farmer. It is measured as the number of years the farmer has obtained formal education. It is expected that, as the farmers attain more formal knowledge, they would be more willing to insure their agricultural assets.

Farm Size: refers to the size of farm being cultivated by the farmer. It is measured as the number of acres being cultivated by the farmer. It is expected that, the larger the farm size of a farmer, the more willing he or she would be to insure his or her agricultural assets. This is because, losses would be very high in the event of a risk.

Unfavorable Weather: defined as the weather conditions which negatively affect productivity. The main components of this variable are flood and drought. Unfavorable weather is measured as the number of times either flood or drought occurred on the farm within the last five planting seasons. It is expected that the occurrence of unfavorable weather would encourage more farmers to insure their agricultural assets.

Fire Outbreak: defined as the situation where fire destroys either some part or the entire part of a farmer's farm. This variable is measured by the number of times fire gutted any portion of the farm within the last five planting seasons. Despite the fact that fire outbreak is a very significant component in agricultural insurance, most of the farmers enumerated have not experienced it. It is therefore expected that, fire outbreak in the Greater Accra Region would not significantly affect the willingness of farmers to insure their agricultural assets.

Income: defined as the average level of annual farm income that farmers derive from their farm through their farming activities within the last five planting seasons. This variable is normally proportional to the farm size with larger farms recording higher farm incomes than the smaller ones. It is expected that, farmers with higher incomes will be encouraged to insure their agricultural assets against huge losses on their farms.

Thefts of Farm Produce: refers to the reduction in productivity or output due to thefts of farm produce. From the data gathered, the farmers indicated that thefts occurred on almost all of the farms with some farmers recording high rates whilst others record very low rates. This variable is measured as the number of times a farmer's produce has been stolen either on the farm or in storage. It is expected that, the occurrence of thefts would encourage farmers to insure their agricultural assets and produce against theft.

Pest and Disease Attacks: defined as the situation where pests or diseases (or both) destroy some part of the farm which results in a significant loss in output. It is measured as the number of times pests or diseases (or both) has affected some part of the farm causing a significant loss within the last five planting seasons. It is expected that, the occurrence of pest and disease attacks would cause farmers to insure their agricultural assets.

The study assumes that, the insurance companies under the GAIP that sell agricultural insurance products are rational and net maximizing firms. It is also assumed that, the farmers enumerated are rational and would want to benefit from the premiums that they would be required to pay.

The theoretical agricultural insurance demand function for the farmer's willingness to insure is therefore given 
by equation 3 as:

$$
\text { AgriIns }=f(\text { Age, Educ, FaSi, Wthr, Fire, Inco, Thef, Pada })
$$

where AgriIns denotes agricultural insurance being supplied by insurance companies, Age denotes the age of a farmer, Educ denotes the level of education of the farmer, FaSi denotes farm size, Wthr denotes unfavorable weather, Inco denotes the income levels of farmers, Thef denotes thefts of agricultural produce and Pada denotes pest and disease attacks on farm produce.

To determine and analyze the factors that affect agricultural insurance, a logistic (logit) regression of the expected factors on agricultural insurance is estimated due to the dummy nature of the dependent variable.

The logistic econometric agricultural insurance willingness to pay model estimated in this study is thus given by equation 4 as:

$$
\begin{gathered}
\log \left(\frac{\text { AgriIns }}{1-\text { AgriIns }}\right)=\beta_{0}+\beta_{1} \text { Age }+\beta_{2} a g e^{2}+\beta_{3} E d u c+\beta_{4} F a S i+\beta_{5} F a S i^{2} \\
+\beta_{6} \text { Wthr }+\beta_{7} \text { Fire }+\beta_{8} \text { Inco }+\beta_{9} \text { Thef }+\beta_{10} \text { Pada }+e_{i}
\end{gathered}
$$

Where:

$\log \left(\frac{\text { AgriIns }}{1-\text { AgriIns }}\right)=$ Log odds of the probability that a farmer will opt for agricultural insurance;

Agrilns = Agricultural Insurance;

The rest of the variables are stated as previously defined.

The Betas $\left(\beta_{1}-\beta_{5}\right)$ are the coefficients and the estimates in this model are in log odds. The marginal effects are then calculated to determine the effects of the factors on the dependent variable.

\section{Data and Descriptive Statistics}

Cross-sectional data is used for the analytical purpose of this study. This comprises primary data collected from five districts in the Greater Accra Region in 2011. Selection of these districts was done randomly. Individual farmers with varied production entities ranging from crops to livestock were interviewed. Farm size was not limited and farmers with different farm sizes were interviewed. Questionnaires with questions focusing on the farm and non-farm activities of the farmers were administered through a face-to-face interview. The dependent variable of the model in this study is farm income. The independent variables estimated include the age, sex, educational level, farm size, farming experience, production type, fertilizer usage, input cost, weather, fire outbreak, theft and pest and disease attacks. Table 2 briefly describes the variables.

Table 2. Variable description and measurement

\begin{tabular}{cllc}
\hline Variable & \multicolumn{1}{c}{ Description } & \multicolumn{1}{c}{ Measurement } & Expected Sign (+/-) \\
\hline FaInco & Farm Income & Continuous (Average Annual Farm Income) & + \\
Age & Age of farmers & Continuous & \pm \\
Sex & Gender of farmer & Dummy (1 if Male; 0 otherwise) & + \\
Educ & Level of education & Continuous (Number of years of formal education) & + \\
FaSi & Farm Size & Continuous (Acres of farm land) & + \\
FaEx & Farming Experience & Continuous (Number of years) & \pm \\
PdnTyp & Production Type & Dummy (0 if Crops, 1 if Animals or 2 if Both) & + \\
Fert & Fertilizer usage & Dummy (1 if farmer uses fertilizer; otherwise 0$)$ & + \\
InpCo & Input Cost & Continuous (Average Annual Cost) & - \\
Wthr & Unfavorable/ Bad Weather & Continuous (Number of times of occurrence) & - \\
Fire & Fire Outbreaks & Continuous (Number of times of occurrence) & - \\
Thef & Thefts of Farm Produce & Continuous (Number of times of occurrence) & - \\
Pada & Pest and Disease Attacks & Continuous (Number of times of occurrence) & + \\
AgriIns & Agricultural Insurance & Dummy (1 if farmer is willing to pay for insurance) & \\
\hline
\end{tabular}

For the willingness to pay agricultural insurance model, the apriori expectations are showed in Table 3. 
Table 3. Apriori expectations for willingness to pay logit model

\begin{tabular}{lll}
\hline Variable & Description & Expected Sign $(+/-)$ \\
\hline AgriIns & Agricultural Insurance & + \\
Age & Age of farmers & + \\
Educ & Level of education & + \\
FaSi & Farm Size & + \\
Wthr & Unfavorable/ Bad Weather & + \\
Fire & Fire Outbreaks & + \\
Inco & Average Income Levels & + \\
Thef & Thefts of Farm Produce & + \\
Pada & Pest and Disease Attacks & + \\
\hline
\end{tabular}

\subsection{Socio-Economic Characteristics of the Farmers}

The farmers interviewed had 73 males and 28 females. Males thus represent about $72.3 \%$ whilst females represent about $27.7 \%$. The ages of the farmers ranged from 21 to 80.33 farmers are within the ages of 21 to 40 representing about $32.7 \%, 51$ are within the ages of 41 to 60 representing about 50.5\% and 17 farmers are within the ages of 61 to 80 representing about $16.8 \%$. The number of years of acquisition of formal education ranged from 0 to 16.15 of the farmers have never been to school before representing about $14.9 \% .20$ farmers fall within the range of 1 year to 5 years of formal education representing about 19.8\%, 45 farmers fall within 6 to 10 years of formal education representing about $44.5 \%$ and 21 of the farmers fall within 11 to 16 years of formal education representing about $20.8 \%$.

Farm size of the farmers ranged from 1 acre to 56 acres. 43 farmers had farms ranging from 1 to 5 acres (Small Scale Farms) representing about 42.6\%, 51 farmers had farms ranging from more than 5 acres to 20 acres (Medium Scale Farms) representing about 50.5\% and 7 farmers had farms greater than 20 acres (Large Scale Farms) representing about $6.9 \%$. For the type of farm cultivated, 49 farmers cultivated only crops, 43 farmers cultivated only livestock and 9 farmers cultivated both crops and livestock.

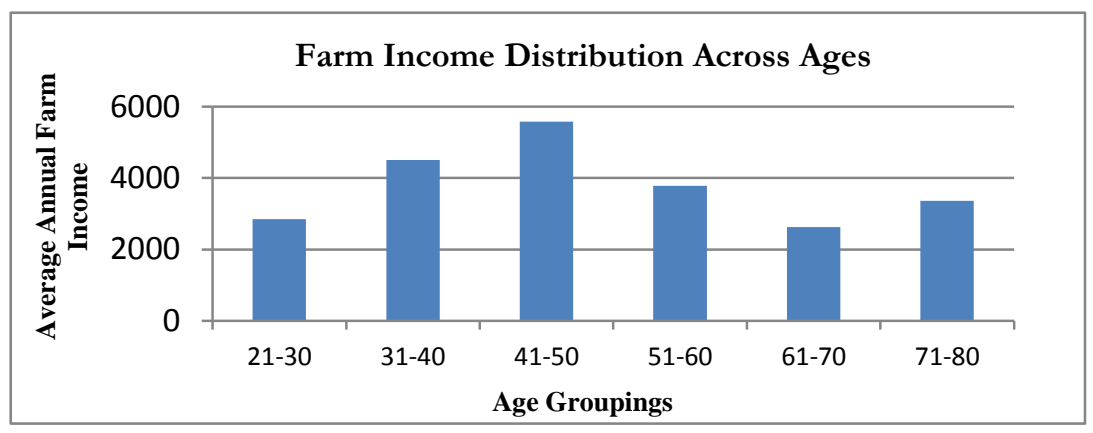

Figure 1. Average farm income distribution of farmers

The graph shows that farmers between the ages of 31 and 50 much more productive than very young and very old farmers. Young farmers between the ages of 20 and 30 and old farmers between the ages of 61 and 70 make the least amount of farm income.

Table 4 below shows the descriptive statistics of the continuous variables with characteristics such as their mean, standard deviation, minimum and maximum values.

Table 4. Descriptive/ summary statistics of continuous variables

\begin{tabular}{lccccc}
\hline \multicolumn{1}{c}{ Variable } & Obs & Mean & Std. Dev. & Min & Max \\
\hline FaInco & 101 & 4196.44 & 1968.25 & 1200 & 9600 \\
Age & 101 & 47.13 & 13.19 & 21 & 80 \\
Educ & 101 & 6.77 & 4.58 & 0 & 16 \\
FaSi & 101 & 9.06 & 8.74 & 1 & 56 \\
FaEx & 101 & 16.42 & 9.10 & 5 & 40 \\
Cost & 101 & 2144.55 & 782.06 & 600 & 4800 \\
\hline
\end{tabular}

*Income and costs are stated in Ghana cedi (Current January 2016 exchange rate: GH $\not 1$ equals \$US 0.26). 


\section{Empirical Results and Discussion}

Table 5 shows the OLS regression results of the logarithmic farm income model presented in Section 3. The White test was used to test for heteroscedasticity and the results show that, the null hypothesis of homoscedasticity was not rejected. This thus indicates that heteroscedasticity was probably not a problem, or at least that if it was a problem, it wasn't a multiplicative function of the predicted values. The Variance Inflation Factor (VIF) was used to detect multicollinearity, and some of the variables had high values. Agesq and Educsq which were insignificant were thus dropped and a subsequent test proved that, the presence of multicollinearly had been corrected. A test for endogeneity was also done, and the result using the Instrumental variable test indicated that, there were no endogenous variables. The Pseudo R-squared value of 0.8681 in shows that, about 86.81 percent of the variation in the dependent variable (farm income) is explained by the independent variables. The probability value $(0.000)$ of the F-statistic shows that, the independent variables exert a significantly joint effect on the amount farm income received by a farmer at the $1 \%$ significance level.

Table 5 also shows that, the age of a farmer, the gender of the farmer, education, farm size, farming experience, the interaction between gender and education, the interaction between farm size and farming experience, input cost, pests and disease attacks and unfavorable weather significantly affect farm. The results imply that, age as a variable has a negative relationship with farm income. An additional year of a farmer reduces his/ her farm income by 0.181 . It is shown that, compared with females, males on the average make a farm income of $8.46 \%$ more than females, all things being equal. A difference in mean analysis for farm income with respect to gender revealed that, males earn $\mathrm{GH} \not 2467.7$ more than females. This result confirms the general assertion in previous studies that, males on the average earn more than females.

Table 5. OLS regression

\begin{tabular}{|c|c|}
\hline Ln_FaInco & Coefficients \\
\hline \multirow[t]{2}{*}{ Age } & $-0.00181 * *$ \\
\hline & $(0.000871)$ \\
\hline \multirow[t]{2}{*}{ Male } & $0.0846^{*}$ \\
\hline & $(0.0441)$ \\
\hline \multirow[t]{2}{*}{ Educ } & $0.0174 * * *$ \\
\hline & $(0.00602)$ \\
\hline \multirow[t]{2}{*}{ MaleEdu } & $-0.00361 *$ \\
\hline & $(0.00252)$ \\
\hline \multirow[t]{2}{*}{$\mathrm{FaSi}$} & $0.0202 * * *$ \\
\hline & $(0.00729)$ \\
\hline \multirow[t]{2}{*}{ FaEx } & $0.00921 * * *$ \\
\hline & $(0.00234)$ \\
\hline \multirow[t]{2}{*}{ FaSiFaEx } & $-0.000335^{* *}$ \\
\hline & $(0.000161)$ \\
\hline \multirow[t]{2}{*}{ livestock } & -0.0203 \\
\hline & $(0.0208)$ \\
\hline \multirow[t]{2}{*}{ Both } & -0.0292 \\
\hline & $(0.0299)$ \\
\hline \multirow[t]{2}{*}{ FertYes } & 0.0144 \\
\hline & $(0.0455)$ \\
\hline \multirow[t]{2}{*}{ ln_ImpCo } & $0.190 *$ \\
\hline & $(0.0996)$ \\
\hline \multirow[t]{2}{*}{ Fire } & -0.0122 \\
\hline & $(0.0502)$ \\
\hline \multirow[t]{2}{*}{ Thef } & -0.00489 \\
\hline & $(0.00980)$ \\
\hline \multirow[t]{2}{*}{ Pada } & $-0.0430 * * *$ \\
\hline & $(0.0124)$ \\
\hline \multirow[t]{2}{*}{ Wthr } & $-0.0497 * * *$ \\
\hline & $(0.0152)$ \\
\hline \multirow[t]{2}{*}{ Constant } & $6.690 * * *$ \\
\hline & $(0.753)$ \\
\hline
\end{tabular}




$\begin{array}{cc}\text { Observations } & 101 \\ \text { Pseudo R-squared } & 0.8681 \\ \text { Root MSE } & 0.0933 \\ \text { F test } & 173.86 \\ \text { Prob(F-statistic) } & 0.0000\end{array}$

$N B: *, * *$ and $* * *$ denotes $10 \%, 5 \%$ and $1 \%$ significance respectively (two-tailed test).

Robust standard errors in parentheses.

The return on education for females is $1.74 \%$ whilst return on education for males is $1.736 \%$ (1.74-0.00361), all things being equal. This result indicates that, contrary to most general previous studies, female farmers in the Greater Accra Region earn a very little more return on education than do males. This can motivate females in the sector to have level of education since the expectation on income is supposed to more.

An additional acre of farm size causes a 1.987 (i.e. 2.02-0.0335) increase in farm income. This result strongly encourages medium scale and large scale farming since small farms would definitely make less income than their bigger competitors, all things being equal.

An additional year of farming experience causes a 0.8875 (i.e. $0.921-0.0335$ ) increase in farm income. This obviously states that, older farmers with more farming experience make more farm income than younger farmers. This therefore implies that, the older farmers used in the data might not have started farming at an early age, since middle aged farmers made the most farm income. This could also be attributed to lesser amounts of vigor and energy for older farmers to farm.

The elasticity between input cost and farm income is 0.19 implying that, a $100 \%$ increase in input cost leads to a $19.86 \%$ increase in farm income. This clearly depicts a decreasing return to scale on these farms.

Among the agricultural insurable risks, pest and disease attacks and unfavorable weather significantly affected the amount of farm income received by the farmers. As expected, they both depicted a negative relationship with farm income with unfavorable weather showing a greater magnitude. The occurrence of a pest or disease attack leads to a 4.30 decrease in farm income whilst the occurrence of an unfavorable weather condition leads to a 4.97 decrease in farm income. From the summary statistics, a farmer faces an average pest and disease occurrence of 2.4 times annually and 2.7 times annually for unfavorable weather. This implies a mean reduction of $10.32(4.30 * 2.4)$ in farm income caused by pest and disease attacks and a mean reduction of $13.42(4.97 * 2.7)$ in farm income caused by unfavorable weather. This results show that, insurance for these risks is indeed very necessary. These results strongly confirm the data used, since most of the farmers either complained about floods or about very low output levels due to attacks from pests and diseases. Most of the farmers noted that they used pesticides and insecticides, and hence this problem could be attributed to either misapplication of these herbicides or the existence of resistant pests and diseases.

The second regression that provides results for the willingness to pay for agricultural insurance model show that, the factors that will significantly affect agricultural insurance in the Greater Accra Region are age-squared, education, unfavorable weather, income and pest and disease attacks.

In what follows, descriptions of the marginal effects of the significant variables are provided (see Tables 6). Findings from the study show that only age-squared, education, unfavorable weather, income levels and pest and disease attacks significantly affect the farmer's willingness towards acquiring agricultural insurance. A result worth noting in this study is the insignificance of fire outbreak in the Greater Accra Region (Note 2). This result stems from the fact that, fire hazards on farms in the Greater Accra Region are very rare and most of the farmers enumerated had not experienced fire outbreaks on their farms ever since they started farming.

Table 6. Binary logit regression and marginal effects of the farmers' willingness to insure their agricultural assets

\begin{tabular}{lcc}
\hline Variable & Coefficients & Marginal effects \\
\hline Age & 0.563 & 0.0488 \\
& $(0.9324)$ & $(0.1586)$ \\
Age square** & 0.1065 & $\mathbf{0 . 0 9 7 9}$ \\
& 0.0405 & $(0.0369)$ \\
Educ** & 1.3395 & $\mathbf{0 . 1 6 9 8}$ \\
& $(0.5551)$ & $(0.0737)$ \\
Fasi & 0.022 & 0.0027 \\
\hline
\end{tabular}




\begin{tabular}{lcc}
\hline & $(0.0317)$ & $(0.0023)$ \\
Fasi square & 0.006 & 0.0009 \\
Wthr** & $(0.0185)$ & $(0.0056)$ \\
& 0.1324 & $\mathbf{0 . 0 4 3 5}$ \\
Fire & $(0.0713)$ & $(0.0212)$ \\
& 0.2322 & 0.0503 \\
Inco* & $(0.8556)$ & $(0.1209)$ \\
& 0.0002 & $\mathbf{0 . 0 0 0 0 4}$ \\
Thef & $(0.0001)$ & $(0.000028)$ \\
& 0.0961 & 0.0214 \\
Pada*** & $(0.1035)$ & $(0.0192)$ \\
& 0.2331 & $\mathbf{0 . 0 5 1 8}$ \\
Constant** & $(0.061)$ & $(0.00422)$ \\
& -0.3617 & \\
Observations & $(0.16076)$ & \\
LR chi ${ }^{2}(5)$ & 100 & \\
F-statistic & 8.85 & \\
Prob(F-statistic) & 2.342 & \\
Log likelihood & 0.034 & \\
Pseudo $\mathrm{R}^{2}$ & -60.319 & \\
$N B$ : * * and $* * *$ denotes $10 \%, 5 \%$ and 1\% significance respectively. &
\end{tabular}

The Pseudo R-squared value of 0.6830 in Table 4.6 means that, about 68.30 percent of the variation in the dependent variable (willingness to insure using agricultural insurance) is explained by the independent variables (age, education, farm size, unfavorable weather, fire outbreaks, income levels, farm thefts and pest and disease attacks). The probability value (0.034) shows that, bad weather, fire outbreaks, income levels of farmers, farm thefts and pest and disease attacks exert a significantly joint effect on farmers' willingness to insure their assets using agricultural insurance at 5\% significance level. As the farmer ages, the probability that the farmer will insure his/her assets using Agricultural Insurance will increase by 0.098, all things being equal. Furthermore, an additional year in the level of education of a farmer increases the probability that a farmer would be willing to insure his/her farm assets by 0.1698 , all things being equal.

Moreover, as the number of unfavorable weather conditions (floods and droughts) increase by 1 , the probability that a farmer will insure his/her agricultural assets using Agricultural Insurance will increase by 0.0435 , all things being equal.

A GH $\not 1$ increase in the level of farm income would increase the probability of insuring agricultural assets by 0.00004 , all things being equal.

Finally, as the number of occurrence of pest and diseases attack increase by 1 , the probability that a farmer will insure his/her agricultural assets using Agricultural Insurance will increase by 0.0518 , all things being equal.

\section{Conclusion}

This article examines the determinants of farm income among farmers in the Greater Accra region of Ghana. This analysis is accomplished by estimating a logarithmic farm income model using a simple OLS regression to determine the effects that the individual determinants exert on the amount of farm income. The econometric results show a highly significant and positive association between farm size and farm income and farming experience and farm income. In addition, gender of farmer, education and input cost also contribute significantly to the improvement of farm revenue all showing a positive relationship. Age, the interaction between gender and education and the interaction between farm size and farming experience also significantly affect farm income, but rather negatively. As was expected, unfavorable weather and pest and disease attacks very much significantly affected farm income negatively.

The study also estimates a Logit model to examine relevant risk factors that that influence willingness to pay for agricultural insurance products. The main policy implication derived from the results of this estimation is an advocacy for agricultural insurance policies that provide an emphasis on unfavorable weather especially flood and pest and disease attacks. Farmers are also advised to guard against these two factors and to correctly use proven preventive measures such as pesticides and avoid planting on hill sides and in valleys. 


\section{References}

Anriquez, G., \& Valdez, A. (2006). Determinants of Farm Revenue in Pakistan. The Pakistan Development Review, 45(2), 281-301.

Biggs, B., Kowaluk, R., Nadeau, J., Partridge, S., \& Rosien, B. (2011). Net Farm Income. Agriculture Economic Statistics, 10(1).

Bravo-Uretaa, B., Sol'1sb, D., Cocchic, H., \& Quiroga, R. (2006). The impact of soil conservation and output diversification on farm income in Central American hillside farming. Agricultural Economics, 35, 267-276. http://dx.doi.org/10.1111/j.1574-0862.2006.00161.x

Danso-Abbeam, G., Addai, K. N., \& Ehiakpor, D. (2014). Willingness to Pay for Farm Insurance by Smallholder Cocoa Farmers in Ghana. Journal of Social Science for Policy Implications, 2(1), 163-183.

El-Osta, H. (2011). The Impact of Human Capital on Farm Operator Household Income. Agricultural and Resource Economics Review, 40(1), 95-115.

Ghana Living Standards Statistics (GLSS) Annual Data. (2008).

Hattink, W., Heerink, N., \& Thijssen, G. (1998). Supply Response of Cocoa in Ghana: A Farm-Level Profit Function Analysis. Journal of African Economies, 7(3), 424-444. http://dx.doi.org/10.1093/oxfordjournals.jae.a020958

Henning, C., \& Henningsen, A. (2007). Modeling Farm Households' Price Responses in the Presence of Transaction Costs and Heterogeneity in Labor Markets. American Journal of Agricultural Economics, 89(3), 665-681. http://dx.doi.org/10.1111/j.1467-8276.2007.00980.x

Institute for Statistical, Social and Economic Research (ISSER) Annual Report. (2014).

Karlan, D., Osei, R., Osei-Akoto, I., \& Udry, C. (2014). Agricultural Decisions after Relaxing Credit and Risk Constraints. The Quarterly Journal of Economics, 129(2), 597-652. http://dx.doi.org/10.1093/qje/qju002

Kwadzo, G. T., Kuwornu, J. K. M., \& Amadu, I. S. B. (2013). Food Crop Farmers' Willingness to Participate in Market-Based Crop Insurance Scheme: Evidence from Ghana. Research in Applied Economics, 5(1). http://dx.doi.org/10.5296/rae.v5i1.2617

Lopez, R., \& Romano, C. (2003). Determinants of Farm Revenue and Factor Returns for Poor Farmers in Brazil. World Bank Country: Rural Poverty Alleviation in Brazil Study, 139-152.

Mabe, K., Antwi, M. A., \& Oladele, O. I. (2010). Factors influencing farm income in livestock producing communities of North-West Province, South Africa. Department of Agricultural Economics and Extension, North-West University.

Ministry of Food and Agriculture (MoFA) Annual Report. (2010).

Mishra, A., \& Paudel, K. (2011). Estimating Permanent Income and Wealth of the US Farm Households. Applied Economics, 43(10-12), 1521-33. http://dx.doi.org/10.1080/00036840802600582

Nunoo, J., \& Acheampong, B. N. (2014). Protecting financial investment: Agriculture insurance in Ghana. Agricultural Finance Review, 74(2), 236-247. http://dx.doi.org/10.1108/AFR-10-2013-0037

Olubiyo, S. O. (2009). Econometric analysis of the impact of agricultural insurance on farming systems in the Middle Belt, Nigeria. African Journal of Food, Agriculture, Nutrition and Development, 9(6). http://dx.doi.org/10.4314/ajfand.v9i6.46266

Stutley, C. (2010). Innovative Insurance products for the Adaptation to Climate Change (IIPACC) Project in Ghana. Ghana: World Bank Publishers.

Wooldridge, J. M. (2008). Introductory Econometrics: A Modern Approach (4th ed.). U.S.A.: South-Western College Publishers.

\section{Notes}

Note 1. Currently, the products provided include drought index insurance for maize, soya, sorghum and millet, as well as multi-peril crop insurance tailor-made to cover the various risks experienced by commercial farmers and plantations.

Note 2. Most farm fire outbreaks occur in the northern part of Ghana where the wind is very dry and the temperature hotter. 


\section{Copyrights}

Copyright for this article is retained by the author(s), with first publication rights granted to the journal.

This is an open-access article distributed under the terms and conditions of the Creative Commons Attribution license (http://creativecommons.org/licenses/by/3.0/). 